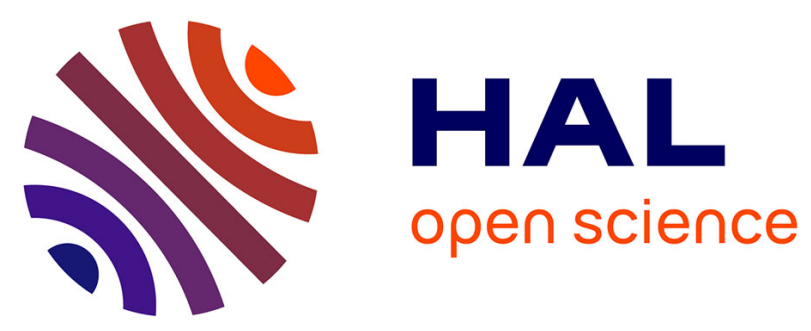

\title{
Multiscale thermal study of virgin and aged polyphenylene sulfide reinforced by glass fiber
}

Peiyuan Zuo, Abbas Tcharkhtchi, Joseph Fitoussi, Mohammadali Shirinbayan, Farid Bakir

\section{- To cite this version:}

Peiyuan Zuo, Abbas Tcharkhtchi, Joseph Fitoussi, Mohammadali Shirinbayan, Farid Bakir. Multiscale thermal study of virgin and aged polyphenylene sulfide reinforced by glass fiber. Journal of Applied Polymer Science, 2020, 10.1002/app.49031 . hal-02539373

\section{HAL Id: hal-02539373 https://hal.science/hal-02539373}

Submitted on 10 Apr 2020

HAL is a multi-disciplinary open access archive for the deposit and dissemination of scientific research documents, whether they are published or not. The documents may come from teaching and research institutions in France or abroad, or from public or private research centers.
L'archive ouverte pluridisciplinaire HAL, est destinée au dépôt et à la diffusion de documents scientifiques de niveau recherche, publiés ou non, émanant des établissements d'enseignement et de recherche français ou étrangers, des laboratoires publics ou privés. 


\title{
Multiscale thermal study of virgin and aged polyphenylene sulfide reinforced by glass fiber
}

\author{
Peiyuan Zuo ${ }^{1}$ @ | Abbas Tcharkhtchi ${ }^{1}$ | Joseph Fitoussi ${ }^{1}$ | \\ Mohammadali Shirinbayan $^{1,2}$ | Farid Bakir $^{2}$
}

\author{
${ }^{1}$ Arts et Metiers Institute of Technology, \\ CNAM, PIMM, HESAM University, \\ F-75013 Paris, France \\ ${ }^{2}$ Arts et Metiers Institute of Technology, \\ CNAM, LIFSE, HESAM University, \\ F-75013 Paris, France \\ Correspondence \\ Peiyuan Zuo, Arts et Metiers Institute of \\ Technology, CNAM, PIMM, HESAM \\ University, F-75013 Paris, France \\ Email: peiyuan.zuo@ensam.eu \\ Funding information \\ China Scholarship Council
}

\begin{abstract}
In this study, virgin and thermal aged PPS samples were prepared and tested using different techniques such as thermogravimetric analysis (TGA), coupled TGA-Fourier transform infrared spectroscopy (FTIR), and FTIR as well as optical microscopy. Some interesting research results can be summarized as follows: TGA results prove the PPS composite samples aged at 180 and $200^{\circ} \mathrm{C}$ have been degraded obviously during the aging period in oven. Moreover, accelerated aging leads to the degradation of PPS composite with the observation of increased thermal oxidation layer from outside to inside. There is a plateau standing at about $350 \mu \mathrm{m}$ for the thermal oxidation layer at oxidation temperature of $200^{\circ} \mathrm{C}$. Some thermal decomposition models are applied to clarify the degradation kinetics of PPS composite. According to the activation energy value, it appears degradation more easily at the beginning of the heating process in the atmosphere of oxygen than that of nitrogen. Moreover, the related products of PPS composites during pyrolysis are fully discussed with the combined analysis of TGA-FTIR techniques.
\end{abstract}

\section{K E Y W O R D S}

ageing, degradation, kinetics, thermal properties, thermogravimetric analysis (TGA)

\section{1 | INTRODUCTION}

The reinforced PPS composites with glass or carbon fibers, exhibit good thermal stability and mechanical strength as well as excellent fatigue resistance, which have been widely used as a high-performance polymer composite material over the recent 40 years. ${ }^{[1-3]}$ In our previous research studies, ${ }^{[4-7]}$ we have comprehensively characterized this PPS composite material and we have fully discussed its fatigue behavior. Moreover, to make better use of this material, it is of importance to pay much attention to degradation behaviors since this aspect directly provides good guidance for the utilization of PPS material in high temperatures or harsh environments.
Thermogravimetric analysis (TGA) is a tool to some research in the field of analyzing polymer degradation. There is a wide range of reports concerning the study of PPS materials by TGA technique. For example, Li et al. ${ }^{[8]}$ studied high-resolution thermogravimetric degradation of PPS film under four atmospheres and they found that there was a dependency among thermal degradation parameters (temperature, the maximal degradation rate), testing atmospheres, and methods. Moreover, the highresolution TGA and derivation of thermogravimetric (DTG) curves of PPS in air exhibited much high resolution than those in helium, argon, and nitrogen. Similarly, the kinetic behaviors concerning PPS pyrolysis under different oxygen concentrations were examined by Teng 
et al. ${ }^{[9]}$ and they concluded that only one stage occurred in inert atmosphere while two stages existed in oxidative atmosphere in the pyrolysis process of PPS. Moreover, Bhardwaj et al. ${ }^{[10]}$ studied the thermal behavior of blended polycarbonate with PPS and they found the activation energy changed when varying the composition of blends. Chang et al. ${ }^{[11]}$ also investigated the stability of two kinds of PPS materials by non-isothermal thermal gravimetric techniques and they concluded that with the increase of heating rate, the initial thermal decomposition temperature of PPS filter media was enhanced and it was of importance to use thermal decomposition activation energy to evaluate the thermal stability of PPS materials. More related research results can be seen in some reference [12], and the authors examined the degradation behavior of semi-crystalline PPS bag-filter materials under $\mathrm{O}_{2}$ at high temperature and they summarized that the strength depended on crystallinity and damages/ defects in amorphous region. Ma et al. ${ }^{[13]}$ studied the thermogravimetric properties of PPS and they found for a crosslinked PPS resin, it existed an interesting temperature in which the degradation rate was retarded due to partial crosslinking of the resin in air. All of these references contribute to our better understanding regarding thermal degradation of PPS materials.

Moreover, when some topics regarding thermal aging of polymers or composites are discussed, an important question flashing in our mind is that whether these materials are thermally stable. To answer this question, it is meaningful to conduct some study with the help of thermal analysis, especially including TGA technique. ${ }^{[14-16]}$ In addition, as a high-performance polymer composite, PPS owns a good ability in aspect of mechanics and thermo-mechanics. As a result, it is very practical to not only investigate extensively the thermal aging on the mechanical properties, but also to explore intensively the thermal degradation or decomposition process when considering the effect of thermal aging. However, over the last several decades, there are few literatures discussing about the thermal properties of PPS polymer or PPS composites based on the performance under long time thermal aging. As a result, PPS, as an excellent structural candidate, which is worth paying more attention in aspect of thermal decomposition behaviors, particularly when the effects of various thermal aging condition are taken into account. ${ }^{[4-7]}$

In this article, the overall thermal behavior of PPS reinforced by glass fiber is discussed to present several information about thermal degradation kinetic and properties of PPS composite. Based on the concerned points, this manuscript is organized as follows: first part is given to the analysis concerning the general degradation process of PPS composite by using TGA and Fourier transform infrared spectroscopy (FTIR) techniques. Subsequently, the oxidized layer is shown and is emphasized with the consideration of the effect of thermal aging. In the end, the main length is focused on the discussion concerning the degradation kinetics according to the results obtained from TGA, FTIR, and TGA-FTIR results.

\section{2 | MATERIALS AND CHARACTERIZATION METHODS}

\section{1 | Materials}

PPS composite materials are kindly supplied by Valeo Company in France. The details about these materials are as follows: The supplied PPS is black plate with a density of $1.58 \mathrm{~g} / \mathrm{cm}^{3}$ and the water absorption for PPS composite is $0.02 \%$. Also, the formation of PPS is shown in Scheme 1. The dog bone-shaped test samples were placed in the ovens (with circulation of air) and the temperatures of aging were chosen from 100 to $260^{\circ} \mathrm{C}$. More research details about this material can be referred in our previous publications. ${ }^{[4-7]}$

\section{2 | Characterization methods}

\subsection{1 | Thermogravimetric analysis}

The thermogravimetric analysis was carried out by TA Q500. PPS samples (between 10 and $20 \mathrm{mg}$ ) were encapsulated in a standard platinum sample pan and virgin PPS composite was heated from room temperature to $800^{\circ} \mathrm{C}$ with different heating rates: $5,15,20$, and $25^{\circ} \mathrm{C} /$ $\mathrm{min}$, respectively. The procedure was carried out in nitrogen and oxygen with a flow of $50 \mathrm{ml} / \mathrm{min}$, respectively. Plot of weight loss was obtained and the kinetic decomposition was studied by various classic models. Also, the PPS samples aged at different temperatures with various aging time were characterized by TGA with a heating rate at $10^{\circ} \mathrm{C} / \mathrm{min}$.

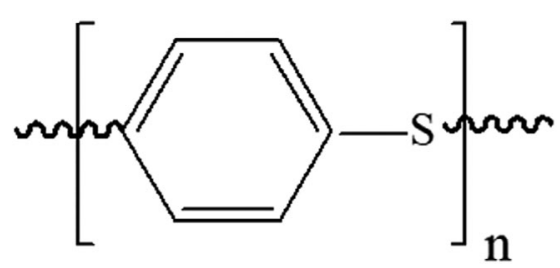

SCHEME 1 The formation of PPS composites used in this study 


\subsection{2 | FTIR analysis}

The principal aim of FTIR spectroscopy is based on the detection of the vibration of chemical bonds for various materials. The vibration frequency depends on the nature of its atoms as well as its chemical environment. This analysis technique makes it possible to determine the nature of chemical bonds. Normally, there are two types of FTIR analysis modes: transmission mode or total reflection model. Here, to consider the whole evolution of chemical bonds in matrix during different thermal aging conditions, it is preferable to make total reflection model into application on plate samples.

\subsection{3 | Optical microscopy analysis}

The cross-sectional micrographs of different samples were observed using an optical microscopy (OM) from ZEISS. The main aim of OM in this study is to measure the thickness of oxidation layer. For each sample, three points are measured to show the average thickness of oxidation layer.

\subsection{4 | Coupled TGA-FTIR analysis}

Thermal mass change has been tested on PPS samples via Coupled TGA-FTIR technique. The temperature program is from room temperature to $1,000^{\circ} \mathrm{C}$ with a heating rate at $10^{\circ} \mathrm{C} / \mathrm{min}$ together with the atmosphere of Nitrogen $(40 \mathrm{ml} / \mathrm{min})$. The original sample mass is $12.324 \mathrm{mg}$, which is put in the $\mathrm{Al}_{2} \mathrm{O}_{3}$ crucible $(85 \mu \mathrm{l})$. During the heating process, the volatile products are detected and analyzed by the coupled FTIR equipment.

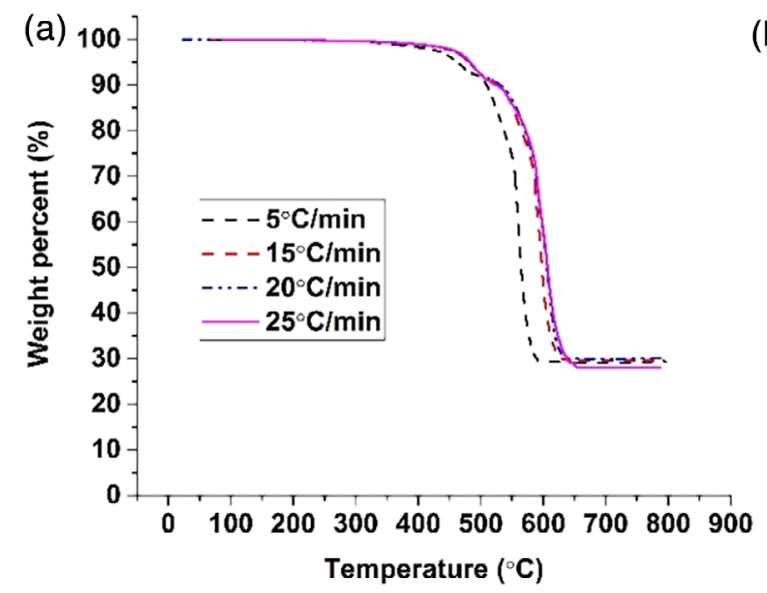

\section{3 | RESULTS AND DISCUSSIONS}

\section{1 | Thermal degradation behavior}

\subsection{1 | Effect of heating rate and atmosphere on TGA curves}

Figure 1 shows the TGA curves of virgin samples at different heating rates under the atmosphere of nitrogen and oxygen, respectively. For the samples heated in nitrogen, it is clear to see that all weight losses consist of two main steps and the weight loss happens in higher temperature with increased heating rate. Comparatively speaking, in oxygen, the samples experienced more complicated multi-steps of degradation, it also can be seen with the heating rate enhancing, the weight loss tends to shift to higher temperature.

\subsection{2 | Effect of aging time and aging temperature}

In this section, it was characterized for the samples with an aging time until $720 \mathrm{hr}$ of oxidation at different aging temperatures (in nitrogen at $10^{\circ} \mathrm{C} / \mathrm{min}$ ) and their TGA curves are shown in Figure 2. One can note that for all samples aged until 1 month $(720 \mathrm{hr})$, they exhibit similar TGA curves. In addition, it can be seen until $720 \mathrm{hr}$ of aging at different temperatures, all samples showed a total weight loss of about $45 \%$ until the heating temperature to $800^{\circ} \mathrm{C}$. Actually, it is worth noting this phenomenon proves the high stability of PPS composite under study.

However, it should also be emphasized that after relatively long time aging $(720 \mathrm{hr})$ at 180 and $200^{\circ} \mathrm{C}$, PPS

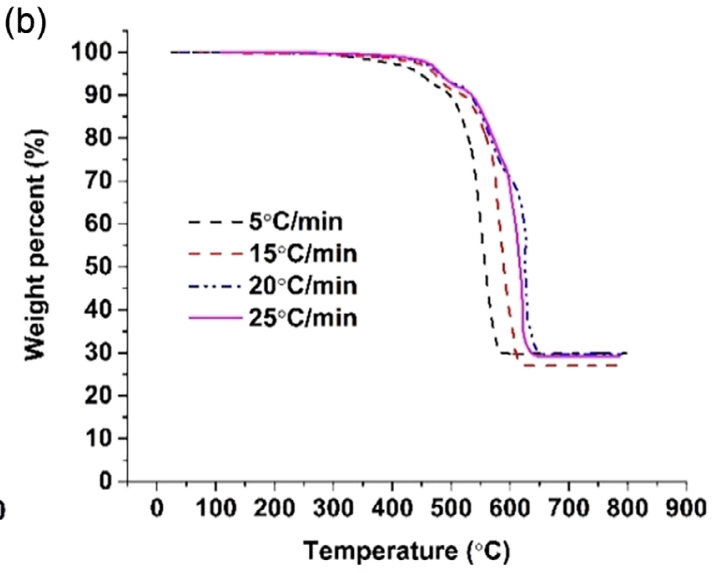

F I G U RE 1 Thermogravimetric analysis (TGA) curves of virgin PPS samples at different heating rates under the atmospheres of nitrogen (a) and oxygen (b) 

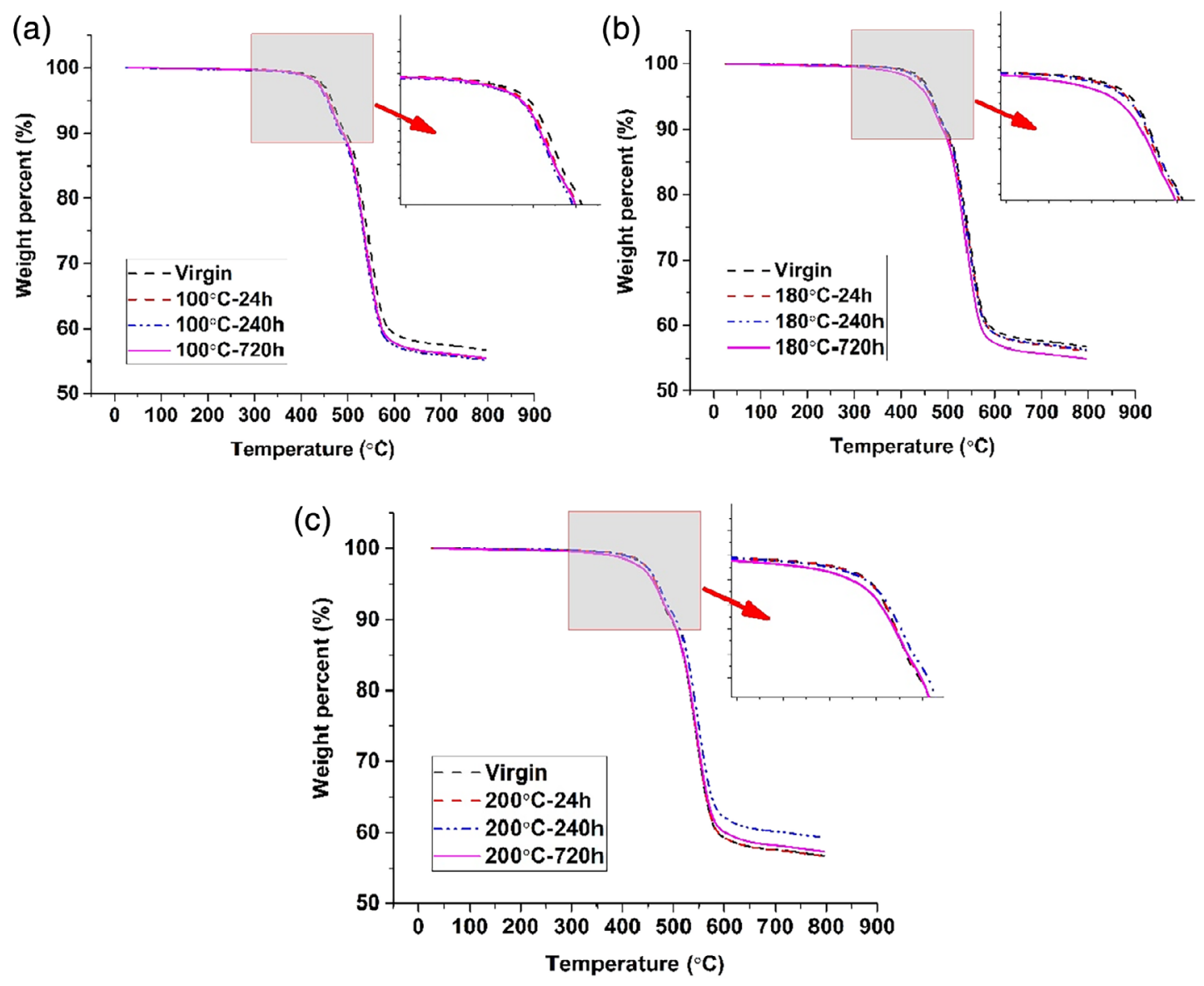

F I G U RE 2 Thermogravimetric analysis (TGA) curves of PPS virgin and aged samples, data obtained from TGA under nitrogen atmosphere at $10^{\circ} \mathrm{C} / \mathrm{min}$. (a)Virgin and aged PPS at $100^{\circ} \mathrm{C}$; (b) virgin and aged PPS at $180^{\circ} \mathrm{C}$; and (c) virgin and aged PPS at $200^{\circ} \mathrm{C}$

composite materials tend to loss its thermal stability since these aged samples appeared degradation or weight lose earlier than the aged samples under lower aging temperatures and shorter aging times (e.g., sample of $100^{\circ} \mathrm{C}$ for $24 \mathrm{hr}, 100^{\circ} \mathrm{C}$ for $240 \mathrm{hr}$ ).

To get a better understanding of long-time aging effect, more aged samples with $3,888 \mathrm{hr}$ of oxidation were studied by TGA technique. Figure 3 shows the TGA curve of virgin and aged PPS samples obtained under the atmosphere of nitrogen. One can obviously note that at the beginning of heating process, there are some differences for virgin and aged samples. Comparatively speaking, virgin and samples aged at $100^{\circ} \mathrm{C}$ for $3,888 \mathrm{hr}$, they have similar weight loss ratio until $300^{\circ} \mathrm{C}$, while the samples aged at 180 and $200^{\circ} \mathrm{C}$ for $3,888 \mathrm{hr}$ have more serious weight loss ratio. In addition, it should be emphasized that this difference tends to be more obvious with the temperature rising. This implies that the samples aged at 180 and $200^{\circ} \mathrm{C}$ have degraded obviously during the aging period in oven and this phenomenon tends to be more pronounced in the case of higher aging temperature.

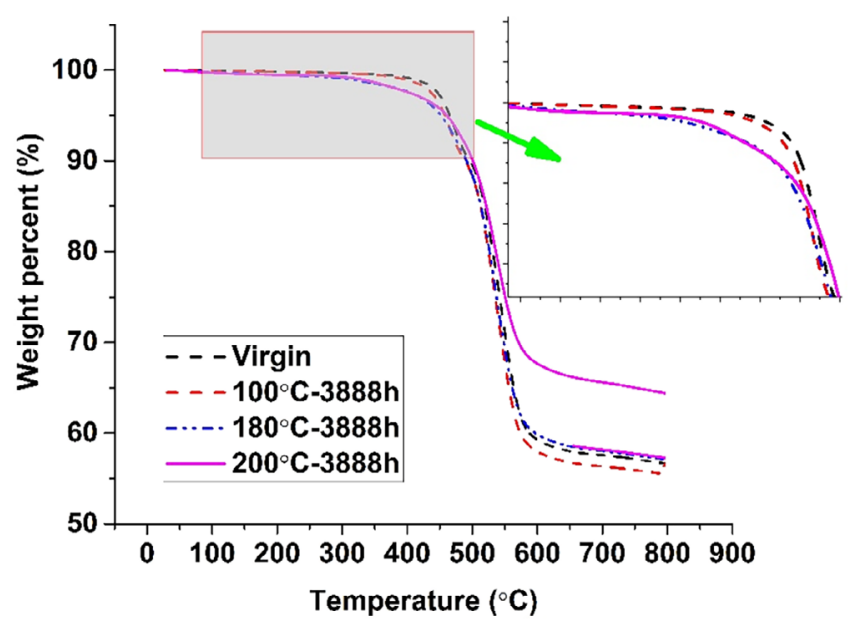

F I G URE 3 Thermogravimetric analysis (TGA) curves of PPS virgin and aged samples under nitrogen at $10^{\circ} \mathrm{C} / \mathrm{min}$ [Color figure can be viewed at wileyonlinelibrary.com]

Derivation of TGA curves for virgin and aged PPS samples are shown in Figure 4. Interestingly, it is very important to figure out that the first derivation peaks 


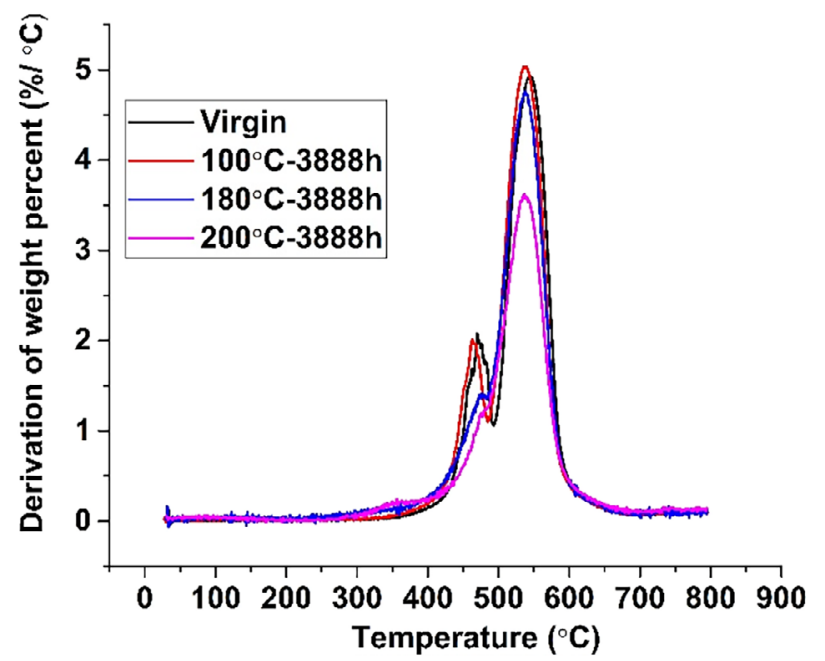

F I G U RE 4 Derivation of thermogravimetric analysis (TGA) curves for virgin and aged PPS samples

arising from the abstraction of $\mathrm{C}-\mathrm{H}$ chemical bonds change very obviously among the virgin and aged samples. More specifically, the first derivation peak for virgin sample is sharp and this corresponding derivation peak becomes more smoothing when the sample was aged at $100^{\circ} \mathrm{C}$ for $3,888 \mathrm{hr}$. Comparatively speaking, when the aging temperature increases to $180^{\circ} \mathrm{C}$, the first derivation peak becomes very weak and finally it almost disappears at $200^{\circ} \mathrm{C}$. This means that during the aging period, this material had experienced degradation and this degree tends to be more serious with the aging temperature up to $200^{\circ} \mathrm{C}$. In addition, during $500^{\circ} \mathrm{C}$ to $600^{\circ} \mathrm{C}$, all samples have simple major peaks, which correspond to the main degradation process of PPS. This indicates that during this aging period, all samples subject to the same degradation mechanism. On the other hand, below $180^{\circ} \mathrm{C}$, the samples have a weight loss of approximately $45 \%$ while the value for sample aged at $200^{\circ} \mathrm{C}(3,888 \mathrm{hr})$ is about $35 \%$. From this aspect, it may imply that the PPS aged $200^{\circ} \mathrm{C}$ experienced irreversible changes, which is obviously distinct to the sample aged in lower temperatures (e.g., $100^{\circ} \mathrm{C}$ ) and virgin sample.

\section{2 | FTIR analysis}

Figure 5 shows the spectrum of virgin and aged PPS samples at 2,160 hr which were aged in different temperatures ranging from 100 to $260^{\circ} \mathrm{C}$. First, it should be emphasized that the absorbance of IR spectrum was measured on reflection mode and this method can exhibit the thermal aging condition of materials. The results suggest that thermal aging have obvious effects on chemical groups of PPS/GF (PPS materials reinforced with short

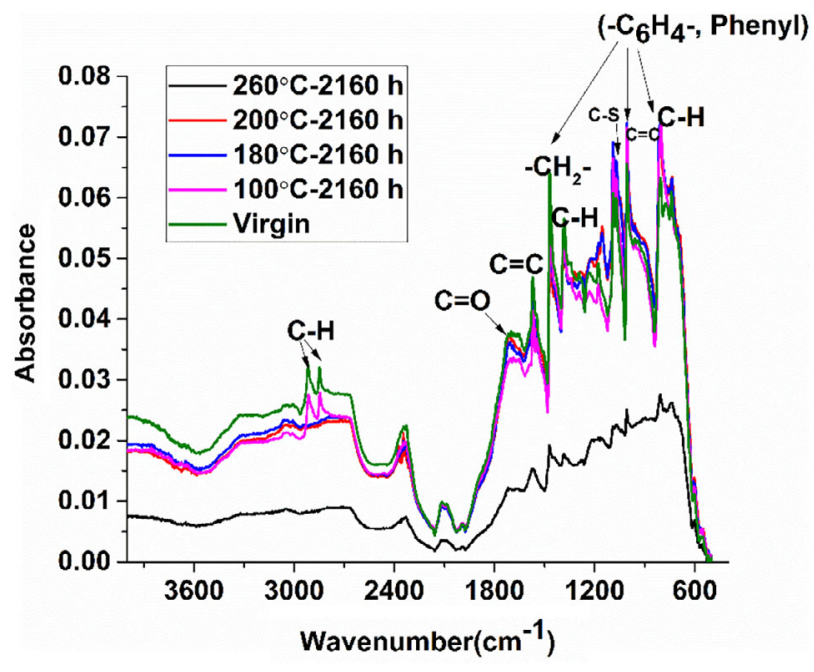

FI G URE 5 Fourier transform infrared spectroscopy (FTIR) spectrum from reflection mode for virgin and aged PPS samples at $2,160 \mathrm{hr}$ in different aged temperatures

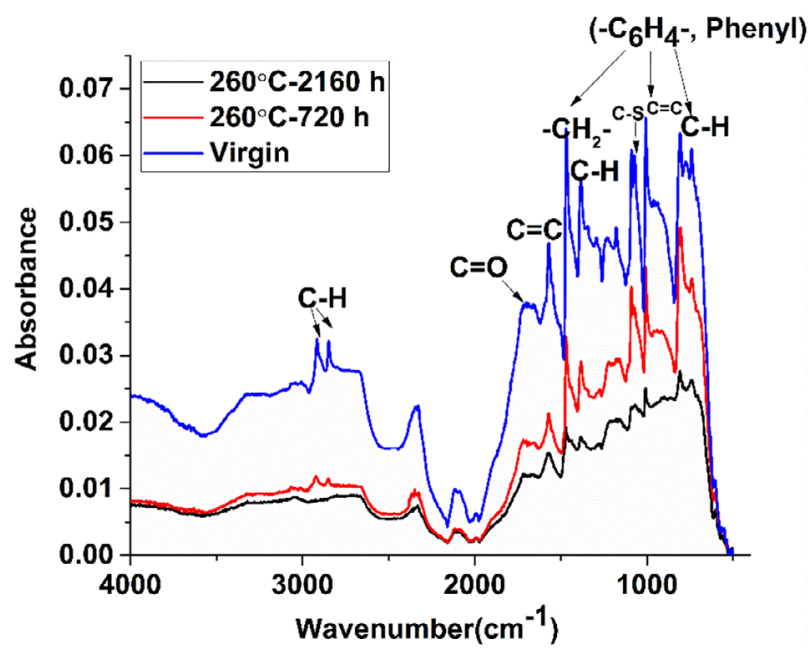

F I G URE 6 Fourier transform infrared spectroscopy (FTIR) spectrum from reflection mode for virgin and aged PPS samples after 720 and $2,160 \mathrm{hr}$ at $260^{\circ} \mathrm{C}$

glass fibers) composite. After 2,160 hr of oxidation, the intensity of absorbance tends to decease qualitatively. In particular, some peaks corresponding to the motions of $\mathrm{C}$ $\mathrm{H}$ bonds (e.g., 2,856 and 2,923 $\mathrm{cm}^{-1}$ ) decrease when the oxidation increases to $180^{\circ} \mathrm{C}$ or higher temperatures. In particular, the oxidation temperature at $260^{\circ} \mathrm{C}$ leads to serious thermal degradation after 2,160 hr, since all peaks can hardly be detected due to weak intensities.

Figure 6 shows the FTIR spectrum evolution for virgin sample and aged samples at $260^{\circ} \mathrm{C}$ after 720 and $2,160 \mathrm{hr}$. One can clearly see that $260^{\circ} \mathrm{C}$ is extremely harsh temperature to the thermal aging process of 

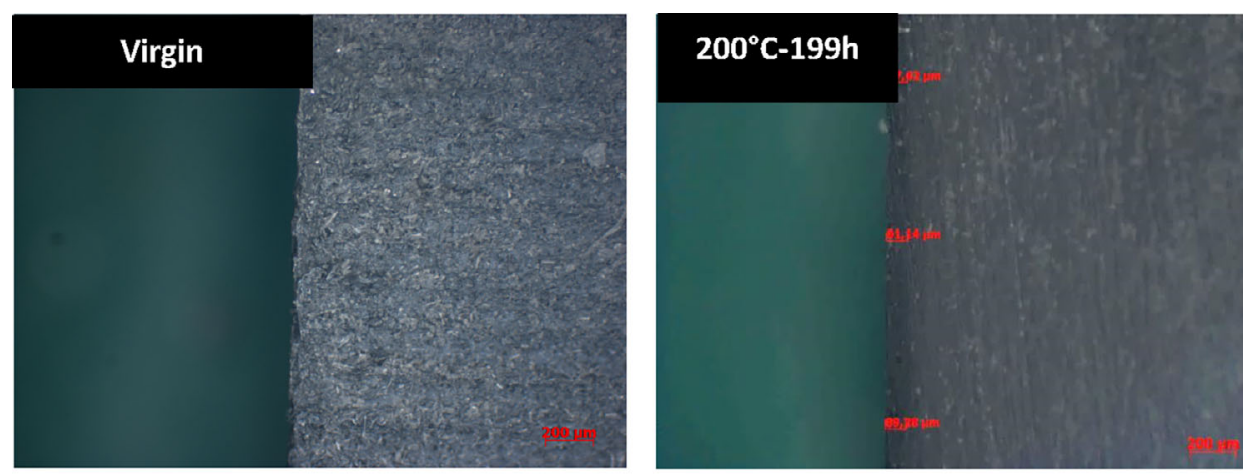

FI G URE 7 Oxidized layer thickness observation of PPS plate by optical microscopy (OM)

$200^{\circ} \mathrm{C}-888 \mathrm{~h}$

$200^{\circ} \mathrm{C}-2160 h$ $200^{\circ} \mathrm{C}-1992 \mathrm{~h}$

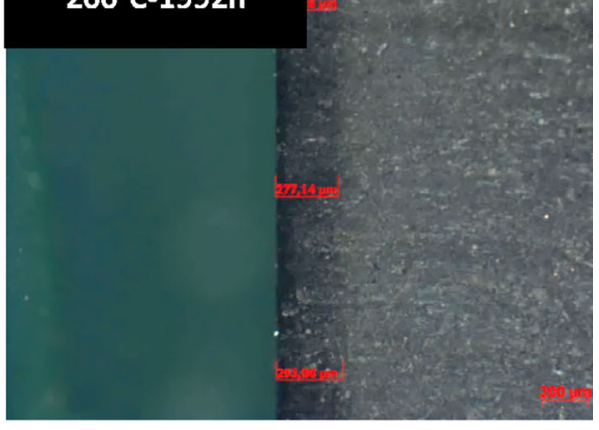

$200^{\circ} \mathrm{C}-3144 \mathrm{~h}$
PPS/GF composite. For the virgin sample, all peaks are distinct and sharp while after $720 \mathrm{hr}$ of oxidation at $260^{\circ} \mathrm{C}$, the absorbance intensity decreases sharply. One can even hardly see the vibrations of $\mathrm{C}-\mathrm{H}$ bonds and the absorbance of whole matrix tend to be reduced due to the serious degradation on the surface of PPS/GF materials. After $2,160 \mathrm{hr}$, the peaks have another further degradation since all peaks continue to decline because the oxygen diffuses into the matrix gradually, which leads to the progressive increase of thermal oxidation layer. The characterization of thermal oxidation layer will be shown in the following section.

\section{3 | Thickness of oxidized layer}

\subsection{1 | Morphological evolution}

Figure 7 gives the evolution of oxidized layer thickness of PPS plates after aging at $200^{\circ} \mathrm{C}$ for different aging time.
One can clearly observe that with the oxidation time increasing, the thickness of oxidized layer tends to increase and the oxidized layer colors tend to be black. Longer aging time is pronounced to darker layer and continuous growth of oxidized layer. One can conclude the accelerated aging results into the degradation of PPS composites from outside to inside and the degradation tend to be more serious with the aging time increasing. The observation result of thermal oxidation layer is consistent with the previous analysis of FTIR and TGA.

\subsection{2 | Quantification of oxidized layer thickness}

Figure 8 records the thickness values according to each three measured points for various aging time at $200^{\circ} \mathrm{C}$. One can note at the beginning the thickness increase sharply from $30 \mu \mathrm{m}$ at $30 \mathrm{hr}$ to more than $275 \mu \mathrm{m}$ with a corresponding aging time at $888 \mathrm{hr}$. Afterward, the 
thickness of oxidized layer tends to be stable and the growth rate become slower due to the slowness of oxygen diffusion in the plate. This suggests that there is a plateau corresponding to final thickness standing at about $350 \mu \mathrm{m}$ at the oxidation temperature of $200^{\circ} \mathrm{C}$ due to the limitation of oxygen diffusion ability.

\section{4 | MODELING OF WEIGHT LOSS EVOLUTION DURING THERMAL AGING}

The application of TGA method holds great promise as a tool for unveiling the mechanisms of physical and chemical processes, which occur during polymer degradation. Here, the TGA method can also be used to explain the processes of polymer degradation after aging. For TGA, the conversion $[\alpha(t)]$ is defined as the ratio of the mass loss at the time $t$ to the total mass corresponding to the particular stage of the degradation:

$$
\alpha(t)=\frac{\left[w_{0}-w_{t}\right]}{\left[w_{0}\right]} * 100 \%
$$

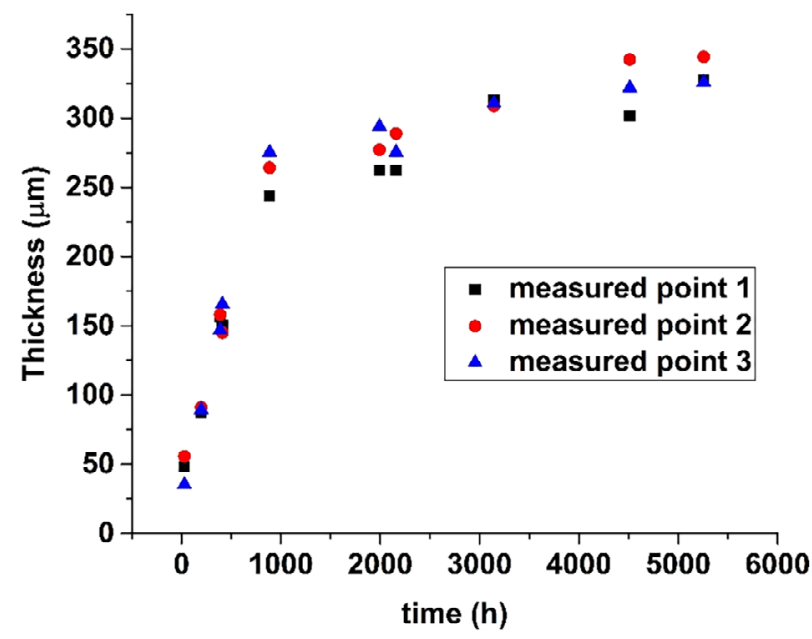

F I G U RE 8 Evolution of thickness of oxidation layer as a function of aging time, at $200^{\circ} \mathrm{C}$ where the values of $w_{0}$ and $w_{t}$ are the initial mass of the sample and the sample mass at the time $t$, respectively.

The rate of conversion in a TGA experiment at a constant heating rate $(\beta)$ can be expressed as:

$$
\frac{d \alpha}{d t}=\frac{A}{\beta} \exp \left(\frac{-E}{R T}\right) \mathrm{f}(\alpha)
$$
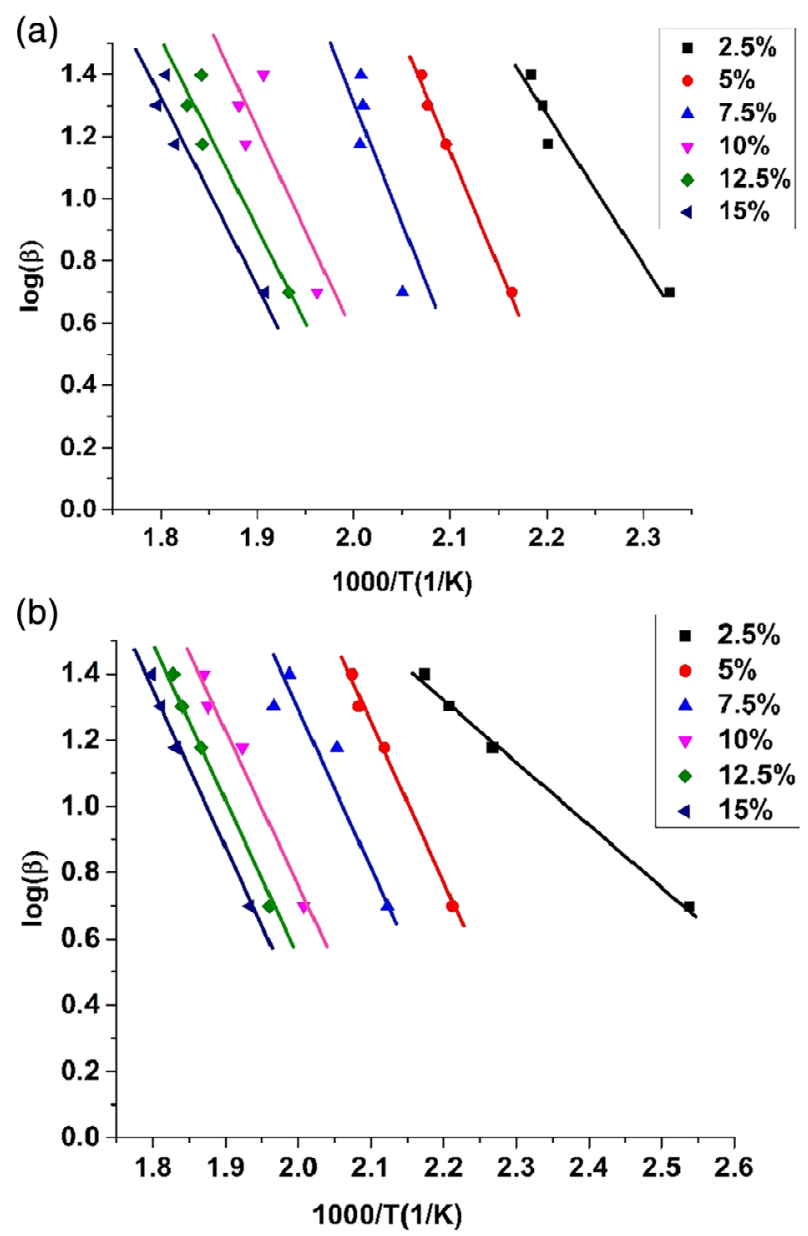

F I G U R E 9 Typical Flynn-Wall-Ozawa plots in the atmosphere of nitrogen (a) and oxygen (b)

\begin{tabular}{|c|c|c|c|}
\hline Method & Expression & Plots & References \\
\hline Kissinger & $\frac{d\left(\ln \left(\beta / T_{m}^{2}\right)\right)}{d\left(1 / T_{m}\right)}=\left(\frac{-E a}{R}\right)$ & $\ln \left(\beta / T_{m}^{2}\right)$ against $\left(1 / T_{m}\right)$ & {$[28,29]$} \\
\hline Friedman & $\ln \left(\frac{d \alpha}{d t}\right)=\ln A+n \cdot \ln (1-\alpha)-\left(\frac{E a}{R \cdot T}\right)$ & $\ln \left(\frac{d \alpha}{d t}\right)$ against $1 / \mathrm{T}$ for a constant $\alpha$ & {$[30]$} \\
\hline Horowitz-Metzger & $\ln \left[\ln \left(\frac{1}{1-\alpha}\right)\right]=\left(\frac{E a \cdot \theta}{R \cdot T_{s}^{2}}\right)$ & $\operatorname{In}(\ln (1-\alpha))$ against $\theta$ & {$[31,32]$} \\
\hline Flynn-Wall-Ozawa & $\frac{-d(\log \beta)}{d\left(\frac{1}{T}\right)}=0.457 \cdot \frac{E a}{R}$ & $d(\log \beta)$ against $d(1,000 / \mathrm{T})$ or $d(1 / \mathrm{T})$ & {$[29,31,33,34]$} \\
\hline
\end{tabular}

T A B L E 1 Theoretical summary list 
T A B L E 2 Activation energies obtained from the conversion rates of 2.5, 5, 7.5, 10, 12.5, and 15\% under the atmospheres of nitrogen and oxygen

\begin{tabular}{|c|c|c|c|c|c|c|}
\hline Conversion (\%) & \multicolumn{3}{|l|}{ Nitrogen } & \multicolumn{3}{|l|}{ Oxygen } \\
\hline 2.5 & $y=-4.1096 x+10.154$ & 75 & .9907 & $y=-1.8692 x+5.4367$ & 34 & .9957 \\
\hline 5 & $y=-4.3197 x+10.261$ & 79 & .9856 & $y=-4.9031 x+11.549$ & 89 & .9938 \\
\hline 7.5 & $y=-4.8053 x+10.98$ & 87 & .9918 & $y=-4.0843 x+9.4457$ & 74 & .8696 \\
\hline 15 & $y=-4.4757 x+9.5913$ & 81 & .9925 & $y=-5.0131 x+10.388$ & 91 & .9944 \\
\hline
\end{tabular}
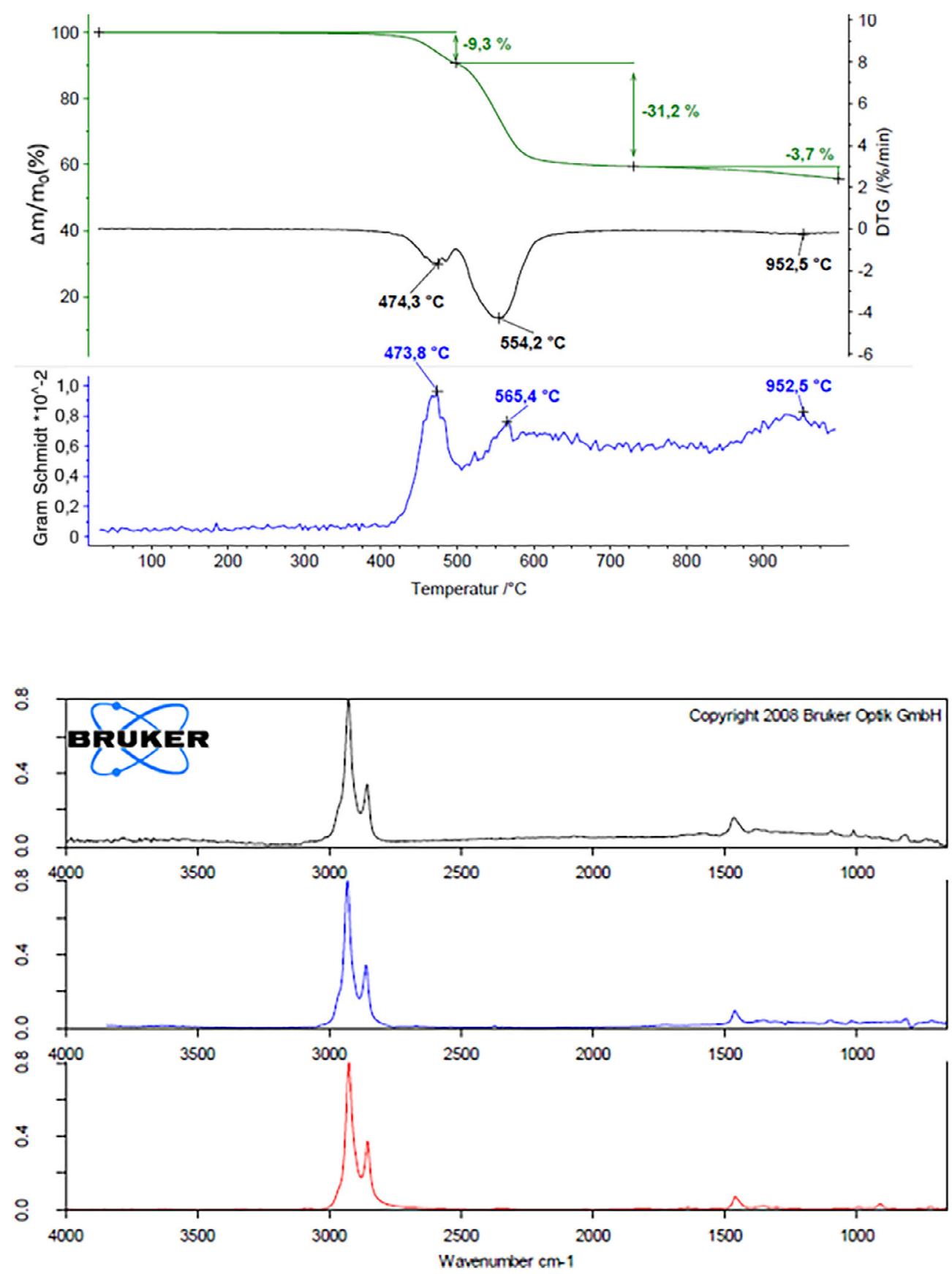

FIGURE 10 Temperaturedependent mass change (TG green) and rate of mass change (derivation of thermogravimetry [DTG], black), Gram-Schmidt curve (purple) of PPS composite
FIGURE 11 Extracted IR spectrum at $474^{\circ} \mathrm{C}$ (black) compared to the database spectrum of PENTACOSANE (blue) and the librarydecomposition spectrum of UHMW-PE (red) 
FIGURE 12 Extracted IR spectrum at $554^{\circ} \mathrm{C}$ (black) compared to the database spectrum of phenyl sulfide (red), thiophenol (blue), and the library-decomposition spectrum of PPS (green)

F IGURE 13 Extracted IR spectrum at $952.5^{\circ} \mathrm{C}$ (black) compared to the database spectrum of carbon disulfide
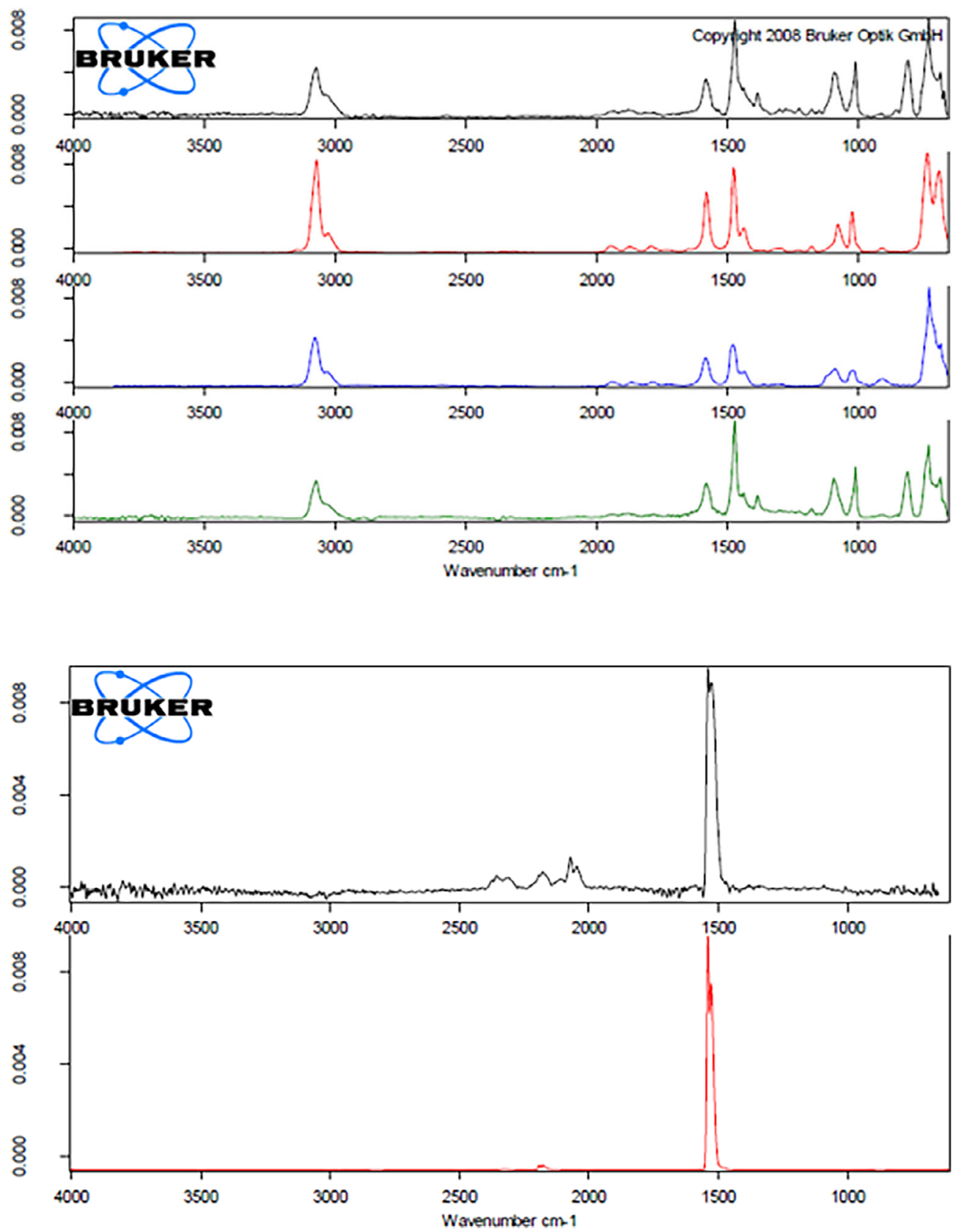

where $T$ is the absolute temperature, $A$ is the preexponential factor, $R$ is the universal gas constant, $\beta$ is the heating rate, $E$ is the activation energy, and $f(\alpha)$ is the conversion functional relationship depending on the particular degradation mechanism.

The integral form of the rate equation is a constant expression experiment may be expressed as:

$$
g(\alpha)=\frac{A}{\beta} \int_{T_{0}}^{T_{p}} e^{-E_{R T}} d T
$$

To get the value of the activation energy and reaction mechanism function, several differential and integral methods have been developed. The most commonly used equations are given as follows (see Table 1):

Figure 9 shows the typical Flynn-Wall-Ozawa plots obtained from the atmosphere of nitrogen and oxygen and the detailed parameters are listed in Table 2 . According to the Flynn-Wall-Ozawa model, the $\log (\beta)$ against $1,000 / \mathrm{T}$ was plotted as a straight line and almost all $R^{2}$ are above .98 regardless of nitrogen or oxygen atmosphere, indicating the high applicability of FlynnWall-Ozawa model to our system.

At the same time, according to the results of fitting Flynn-Wall-Ozawa plots, the activation energy is calculated and shown in Table 2 . The activation energy varies between 70 and $90 \mathrm{~kJ} / \mathrm{mol}$ in the atmosphere of nitrogen. 
Comparatively speaking, this value for $2.5 \%$ conversion of degradation in oxygen is only $34 \mathrm{~kJ} / \mathrm{mol}$ and afterward this value varies between 70 and $100 \mathrm{~kJ} / \mathrm{mol}$ with the conversion percent rising. This indicates at the beginning of degradation in the atmosphere of oxygen, it is easier to happen than the case in nitrogen since the activation energy value in nitrogen is $75 \mathrm{~kJ} / \mathrm{mol}$ (2.5\% conversion), which is two times than the value in oxygen at the same conversion level.

\section{5 | ANALYSIS OF THERMAL PYROLYSIS PRODUCTS BY TGA- FTIR TECHNIQUE}

In practice, the PPS composites should serve in harsh temperatures and it is of importance to figure out the degradation mechanism at high temperature up to melting point and also it seems very significant to get a better understanding of pyrolysis products for every temperature period by TGA-FTIR technique. ${ }^{[14,15,17,18]}$ This TGA-FTIR analysis below gives practical guidance to the wide usage of PPS composites. ${ }^{[19-27]}$ Figure 10 depicts the temperature-dependent TGA-FTIR curves with the applied thermal treatment by heating in inert atmosphere up to $850^{\circ} \mathrm{C}$, which result into three mass loss steps of $-9.3,-31.2$, and $-3.7 \%$ with peaks in the DTG curve (mass loss rate) at $474.3,554.2$, and $952.5^{\circ} \mathrm{C}$. The GramSchmidt curve displays the overall IR intensities and behaves as a mirror image of the mass loss rate (DTG) and shows maximum intensities during mass loss steps.

For detailed evaluation of the in situ IR data, single spectra were taken at each mass loss step and compared to the EPA-NIST database and the NETZSCH TGA-FTIR database of polymer (see Figures 11-13). The first mass loss step is mostly characterized by a release of a variety of hydrocarbons. Figure 11 shows therefore the library spectrum of PENTACOSANE as comparison example. The first step itself shows in total a good correlation to the decomposition spectrum of a pure polyolefin like polyethylene, which underlines the fact of the release hydrocarbon species. This suggests that in PPS composite under enough high temperature, first there are some degradation in the position of $\mathrm{C}-\mathrm{H}$ or $\mathrm{C}-\mathrm{S}$ bonds, thus to produce radicals like hydrocarbon species. However, it is worth noting the mass loss in the first period of degradation is $-9.3 \%$.

The second mass loss step (see Figure 12) is accompanied by a release of phenyl sulfide and thiophenol and shows the expected correlation to the library decomposition spectrum of PPS. In second period it is the main degradation period of PPS since the mass loss rate is the maximum up to $-31.2 \%$, and this also means in this period the main chain scissions degrade sharply and numerous radicals are produced and recombined again. Depolymerization is the main phenomenon in this period.

In the third step, it also detects some species like carbon disulfide (see Figure 13). It is interesting to note residues like hydrocarbon radicals, sulfur radicals, or carbons radicals recombine together to produce carbon sulfide species in high temperature (above $800^{\circ} \mathrm{C}$ ). This process is very complicated since various residues are produced or reacted with other products.

\section{6 | CONCLUSIONS}

In this study, virgin and aged PPS samples were prepared and tested using TGA, TGA-FTIR, and FTIR as well as $\mathrm{OM}$ techniques and the main conclusions are as follows:

Concerning degradation behavior, the first derivation peak for virgin sample is sharp and this derivation peak becomes more smoothing when the sample was aged at $100^{\circ} \mathrm{C}$ for $3,888 \mathrm{hr}$, while the first derivation peak nearly disappears at $200^{\circ} \mathrm{C}$. In addition, the main degradation process comprises two steps in nitrogen while in oxygen atmosphere, it exhibits multisteps of degradation during a wide temperature range $\left(450-650^{\circ} \mathrm{C}\right)$ and these derivation peaks are very sharp and do not exhibit normal distribution.

Moreover, accelerated aging leads to the degradation of PPS composites little by little from outside to inside according to the observation of increased thermal oxidation layer. In addition, there is a plateau corresponding to thickness value standing at about $350 \mu \mathrm{m}$ at the oxidation temperature of $200^{\circ} \mathrm{C}$.

Furthermore, the $\log (\beta)$ against $1,000 / \mathrm{T}$ was plotted as a straight line and the Flynn-Wall-Ozawa model can be applied in our PPS system. Also, according to the activation energy value, it is easier to appear degradation at the beginning of heating process in the atmosphere of oxygen, than that in nitrogen. In addition, the TGA-FTIR technique helps us to get a better understanding of detailed products during pyrolysis process of PPS composite materials.

\section{ACKNOWLEDGMENTS}

The authors are grateful to Dr R. C. Benevides and Dr M. Henner (Valeo) for collaboration and fruitful discussions. Valeo Company is also gratefully acknowledged for providing the material. Financial support from the CASCADE program under project "FSN Calcul Intensif et Simulation Numérique" by DGE is gratefully acknowledged. The authors also thank China Scholarship Council (CSC) for their funding of Peiyuan Zuo's thesis. 


\section{ORCID}

Peiyuan Zuo @ https://orcid.org/0000-0003-3140-8650

\section{REFERENCES}

[1] H. W. Hill, D. Brady, Polym. Eng. Sci. 1976, 16, 831.

[2] L. Caramaro, B. Chabert, J. Chauchard, T. Vu-Khanh, Polym. Eng. Sci. 1991, 31, 1279.

[3] M. Favaloro, SAE Technical Paper: No. 2009-01-3242, 2009.

[4] P. Zuo, R. C. Benevides, M. A. Laribi, J. Fitoussi, M. Shirinbayan, F. Bakir, A. Tcharkhtchi, Compos. Part B: Eng. 2018, 145, 173.

[5] P. Zuo, A. Tcharkhtchi, M. Shirinbayan, J. Fitoussi, F. Bakir, Macromol. Mater. Eng. 2019, 304, 1800686.

[6] P. Zuo, J. Fitoussi, M. Shirinbayan, F. Bakir, A. Tcharkhtchi, Polym. Eng. Sci. 2019, 59, 765.

[7] P. Zuo, A. Tcharkhtchi, M. Shirinbayan, J. Fitoussi, F. Bakir, Polym. Adv. Technol. 2019, 30, 584.

[8] X. G. Li, M. R. Huang, H. Bai, Y. L. Yang, J. Appl. Polym. Sci. 2002, 83, 2053.

[9] C. Teng, J. Liu, N. Mao, X. Tian, International Conference on Chemical, Material and Food Engineering (CMFE-2015) 2015.

[10] I. Bhardwaj, V. Kumar, A. Das, Thermochim. Acta 1989, 144, 165.

[11] D. Q. Chang, J. X. Liu, N. Mao, B. Z. Chen, Adv. Mater. Res. 2013, 663, 988.

[12] W. Tanthapanichakoon, M. Furuuchi, K.-H. Nitta, M. Hata, S. Endoh, Y. Otani, Polym. Degrad. Stab. 2006, 91, 1637.

[13] C.-C. M. Ma, H.-C. Hsia, W.-L. Liu, J.-T. Hu, J. Thermoplast. Compos. Mater. 1988, 1, 39.

[14] S. Singh, C. Wu, P. T. Williams, J. Anal. Appl. Pyrol. 2012, 94, 99.

[15] B. Baruah, P. Tiwari, P. Thakur, R. Kataki, J. Anal. Appl. Pyrol. 2018, 135, 397.

[16] C. Quan, N. Gao, Q. Song, J. Anal. Appl. Pyrol. 2016, 121, 84.
[17] A. Marcilla, M. I. Beltran, A. Gómez-Siurana, I. MartinezCastellanos, D. Berenguer, V. Pastor, A. N. García, J. Anal. Appl. Pyrol. 2015, 112, 48.

[18] M. A. Corres, M. Zubitur, M. Cortazar, A. Múgica, J. Anal. Appl. Pyrol. 2011, 92, 407.

[19] D. Lian, J. Ren, W. Han, C. Ge, J. Lu, J. Mol. Struct. 2019, 1196, 734.

[20] J. Xing, Q.-Q. Ni, B. Deng, Q. Liu, Compos. Sci. Technol. 2016, 134, 184.

[21] K. Stoeffler, S. Andjelic, N. Legros, J. Roberge, S. B. Schougaard, Compos. Sci. Technol. 2013, 84, 65.

[22] H. Xu, Z. Feng, J. Chen, H. Zhou, Mater. Sci. Eng.: A 2006, 416, 66.

[23] E. Schuhler, A. Coppalle, B. Vieille, J. Yon, Y. Carpier, Polym. Degrad. Stab. 2018, 152, 105.

[24] K. Kim, J. Kim, Compos. Sci. Technol. 2016, 134, 209.

[25] X. Yang, L. Tang, Y. Guo, C. Liang, Q. Zhang, K. Kou, J. Gu, Compos. Part A: Appl. Sci. Manuf. 2017, 101, 237.

[26] Y. F. Zhao, M. Xiao, S. J. Wang, X. C. Ge, Y. Z. Meng, Compos. Sci. Technol. 2007, 67, 2528.

[27] K. Kim, J. Kim, Polymer 2016, 101, 168.

[28] H. E. Kissinger, Anal. Chem. 1957, 29, 1702.

[29] Y. Chen, Q. Wang, Polym. Degrad. Stab. 2007, 92, 280.

[30] A. Jimenez, V. Berenguer, J. Lopez, A. Sanchez, J. Appl. Polym. Sci. 1993, 50, 1565.

[31] W. F. Lee, J. Appl. Polym. Sci. 1989, 37, 3263.

[32] H. H. Horowitz, G. Metzger, Anal. Chem. 1963, 35, 1464.

[33] J. H. Flynn, L. A. Wall, J. Polym. Sci. Part C: Polym. Lett. 1966, 4, 323.

[34] T. Ozawa, Bull. Chem. Soc. Japan 1965, 38, 1881. 